\title{
Communities of Solution: Partnerships for Population Health
}

\author{
Kim S. Griswold, MD, MPH, Sarah E. Lesko, MD, MPH, and John M. Westfall, MD, MPH, for \\ the Folsom Group
}

Communities of solution (COSs) are the key principle for improving population health. The 1967 Folsom Report explains that the coS concept arose from the recognition that complex political and administrative structures often hinder problem solving by creating barriers to communication and compromise. A 2012 reexamination of the Folsom Report resurrects the idea of the COS and presents 13 grand challenges that define the critical links among community, public health, and primary care and call for ongoing demonstrations of COSs grounded in patient-centered care. In this issue, examples of coSs from around the country demonstrate core principles and propose visions of the future. Essential themes of each COS are the crossing of "jurisdictional boundaries," community-led or -oriented initiatives, measurement of outcomes, and creating durable connections with public health. ( $\mathrm{J}$ Am Board Fam Med 2013;26:232-238.)

Keywords: Connecting Communities: Public and Personal Health

Communities of solution (COSs) are the key principle for improving population health. The COS concept as presented in the 1967 Folsom Report ${ }^{1}$ arose from the recognition that complex political and administrative structures often hinder problem solving by creating barriers to communication and compromise. The Folsom Report emphasized that a community's "problem sheds" bear little relation to its political, municipal, or health care jurisdictional boundaries. Per the original Folsom Report, a problem shed was described like a watershed, that is, the contributing factors that combine to create a health care or public health problem. For example, for a spike in asthma hospitalizations, the problem shed may involve a pulp mill 20 miles away, the closure of a community health center, a cock-

From the Department of Family Medicine, State University of New York at Buffalo, School of Medicine and Biomedical Sciences, Primary Care Research Institute, Buffalo (KSG); Seattle, WA (SEL); and Department of Family Medicine, University of Colorado School of Medicine, Aurora, CO (JMW).

Funding: none.

Conflict of interest: none declared.

Corresponding author: Kim S. Griswold, MD, MPH, Department of Family Medicine, 77 Goodell St., Buffalo, NY 14203 (E-mail: griswol@buffalo.edu). roach infestation in public housing, and an outbreak of a respiratory illness. The COS would need to encompass all these factors to best be able to address the health problem. Boundaries of each community should ideally be established by "the boundaries within which a problem can be defined, dealt with, and solved."

A 2012 reexamination of the Folsom Report ${ }^{2}$ resurrects the idea of the COS and presents 13 grand challenges (Table 1), which define the critical links among community, public health, and primary care and call for ongoing demonstrations of COSs grounded in patient-centered care. "Defragmenting and improving the value of health care both require a system that fosters non-medical determinants of health. Here, individualized, whole patient-centered, and community-based, integrated, multi-professional based efforts can succeed where individualistic, specialty, and medical care centered systems have failed."

In this issue, examples of COSs from around the country demonstrate core principles and propose visions of the future. Essential themes of each COS include the crossing of "jurisdictional boundaries," community-led or -oriented initiatives, measurement of outcomes, and creating durable connections with public health. We have 
Table 1. Grand Challenges for Integrating Community Health Services

Folsom Report Recommendations 1967

A. Organization and delivery of community health services "community of solution" by relevant administrative area, not by political (city, county, state) jurisdictions

B. Provision of high-quality comprehensive personal health services to all people in each community

C. Every individual should have a personal physician who is the central point for integration and continuity of all medical and related services to the patient

D. Prospective planning and management of comprehensive environmental health services; includes water, air, food, hygienic housing, activity, and recreation
Grand challenge 1: Create a national network of community partnerships that engages and activates the citizenry to self-define Communities of Solution in order to develop and sustain community-tailored health programs at the local level aimed at matching local health needs with integrated health services.

Grand challenge 2: Foster the ongoing development of integrated comprehensive care practices (patient-centered medical homes) accessible for all groups in a community-through the creation of explicit partnerships with public health professionals and Communities of Solution.

Grand challenge 3: Provide every individual in the United States the opportunity to form a partnership with a personal physician and a team of health professionals utilizing integrated community health services in Communities of Solution.

Grand challenge 4: Engage individuals in Communities of Solution in the creation of healthy environments, eliminating existing barriers to community-tailored strategies; and endorse and implement a global conception of environmental health encompassing all physical, chemical, and biological factors external to a person that can potentially affect health.
Funded Provisions from the American Recovery \& Reinvestment Act of 2009, Children's Health Insurance Program Reauthorization Act of 2009, and Patient Protection \& Affordable Care Act of 2010

PPACA: Community-based Collaborative Care Network Program; National Prevention, Health Promotion \& Public health Council, chaired by the U.S. Surgeon General, to coordinate federal prevention, wellness, and public health activities and to "elevate and coordinate prevention activities and design a focused National Prevention and Health Promotion Strategy in conjunction with communities across the country to promote the nation's health. The Strategy will take a community health approach to prevention and well-being-identifying and prioritizing actions across government and between sectors"; Community Transformation Grants

ARRA: Increased funding for CHCs, military hospitals, Veterans Administration, Indian reservations, NHSC, and Consolidation Omnibus Budget Reconciliation Act (COBRA) subsidies

CHIPRA: Coverage of additional 4.1 million children

PPACA: Patient-centered medical home demonstration project within the Centers for Medicare \& Medicaid Services; Medicaid parity with Medicare; increased insurance access

ARRA: Funding for wellness and prevention

CHIPRA: Funding for outreach, translation, interpretation; demonstrations to combat obesity

PPACA: Preventive health care coverage mandate; \$250 million Prevention and Public Health Fund to community programs (including National Healthy Weight Collaborative); interagency council headed by surgeon general with focus on prevention and public health

PPACA: Community Preventive Services Task Force 
E. Ensure control of water and air pollution, biological and chemical product safety, radioactive material safety

F. Accident prevention:

- State health departments should develop accident prevention programs.

- U.S. Public Health Service should establish a national accident prevention, research, training, service, and information facility analogous to the present communicable disease center.

G. Family planning should be an integral part of community health services

H. Coordinate land use, transportation, economic development, and city planning to provide most effective and space use for urban populations

I. Education for health:

- The community has a responsibility for developing an organized and continuing education concerning health resources for its residents.

- Each individual has a personal responsibility for making full use of available health resources.

J. Health manpower: effective utilization of available health personnel will reduce the current manpower shortage, and continuous evaluation of the use of manpower, accompanied by necessary changes and retraining, will provide additional manpower for existing new health services

K. Hospital care: further increases in hospital costs must not be accepted complacently, but that a wide range of vigorous and persistent actions must be taken by all parties concerned to moderate the costs of hospital care without adverse effects on quality

L. Every state should have a single, strong, well-financed, professionally staffed, official health agency with sufficient authority and funds to carry out its responsibilities/ assure every community of coverage by an official health agency and access to a complete range of community health services

M. Voluntary citizen participation: a central factor in the growth and development of ... personal and community health has been the participation of individuals and voluntary associations through dedicated leadership, financial support, and personal service
Grand challenge 5: Engage

Communities of Solution to recognize and address injuries as a main preventable source of global human death and disability—especially for children.

Grand challenge 6: Sustain and improve family planning as an integral part of community health services.

Grand challenge 7: Engage with community partnerships to coordinate with municipal authorities to design and build healthy living environments.

Grand challenge 8: Enhance health literacy to empower individuals within Communities of Solution to be active participants in promoting their own health and the health of their communities.

Grand challenge 9: Create a health workforce to serve the needs of U.S. communities.

Grand challenge 10: Integrate health services-aligning hospital, ambulatory, and community careacross settings to promote quality and create value.

Grand challenge 11: Transform the roles of the relevant federal, state, and local agencies by bridging public health and medicine to be effective partners in communities of solution.

Grand challenge 12: Engage and support a citizen volunteer network formed by Communities of Solutions to educate, motivate and collaborate for strategic local, regional, and national resource allocation informed by credible and actionable data.
PPACA: State eligibility option for family planning services

PPACA: Community Preventive Services Task Force

PPACA: Health care quality improvement programs; health care delivery system research; funding available for health literacy research

ARRA: NHSC expansion

PPACA: Teaching health centers; Primary Care Extension Service; revisions to GME to favor nonhospital training; national healthcare workforce commission to align federal workforce resources with needs; preference of primary care for reallocation of unused graduate medical education slots

PPACA: Establishment of accountable care organization pilots to manage patient populations comprehensively across settings

PPACA: Research on optimizing the delivery of public health services; Prevention and Public Health Fund

Title IV, Prevention of Chronic Diseases and Improving Public Health 


\begin{tabular}{|c|c|c|}
\hline $\begin{array}{l}\text { N. Action planning for community health } \\
\text { services: planning is an action process } \\
\text { and is basic to development and } \\
\text { maintenance of quality community } \\
\text { health services }\end{array}$ & $\begin{array}{l}\text { Grand challenge 13: Utilize health } \\
\text { information technology and } \\
\text { emerging data-sharing innovative } \\
\text { networks that enable the flow of } \\
\text { relevant knowledge (public health, } \\
\text { environmental, educational, legal, } \\
\text { etc.) to the Communities of } \\
\text { Solution. }\end{array}$ & $\begin{array}{l}\text { ARRA: Beacon Community Cooperative } \\
\text { Agreement Program } \\
\text { PPACA: National Prevention, Health } \\
\text { Promotion \& Public Health Council } \\
\text { (see above); implementation of } \\
\text { activities to improve patient safety and } \\
\text { reduce medical errors through the } \\
\text { appropriate use of best clinical } \\
\text { practices, evidence-based medicine, } \\
\text { and health information technology }\end{array}$ \\
\hline
\end{tabular}

*The grand challenges address each of the major recommendations from "Health is a Community Affair" and overlapping provisions from recent legislation.

CHC, community health centers; GME, graduate medical education; NHSC, National Health Service Corps.

Adapted or reprinted with permission from Stange KC. In this issue: from communities of solution to joy. Ann Fam Med. 2012;10(3): 194-195. The Folsom Group. Communities of solution: the Folsom Report revisited. Ann Fam Med. 2012;10(3):250-260., July/August, 2012, Vol 10, No 4, Annals of Family Medicine, ${ }^{2} 2012$ American Academy of Family Physicians. All Rights Reserved.

linked each article with the respective grand challenge(s) that are addressed.

\section{Engaging Stakeholders: Crossing Boundaries}

In "Advanced Primary Care in San Antonio," Ferrer et $\mathrm{al}^{3}$ utilize health promotion promotores to create relationships with patients in the community, and they engage city planners to map community resources and community partners for each patient's neighborhood and thereby tap into community resources to maximize health (grand challenges 2, 7, 8, and 10, presented in Table 1). The essential tracking of health outcomes, although early, is an essential piece of the COS. The Brazos Valley Health Partnership COS involves the establishment of "one-stop shops" that provide patients with services ranging from health care to Senior Meals to legal aid. Because of the difficulty accessing services experienced by these rural community members, Garney et $\mathrm{al}^{4}$ explain that "county boundaries are irrelevant with regard to social and health issues that residents face" (grand challenges 2, 4, 8, 10, and 11). This COS reveals the importance of involving numerous sectors of the community, including community-based organizations, governmental leaders, and health care providers (Figure 1).

In "Boot Camp Translation" the High Plains Research Network ${ }^{5}$ describes the process for identifying health problems and then building a COS to translate the best medical evidence into locally relevant and actionable projects. The High Plains Research Network brings together patients, community members, health care pro- viders, public health agencies, and communitybased organizations to address the important health issues of their populations. This process relies on the expertise of everyone, in both academia and the community, to develop a local solution (grand challenges 2, 4, 8, 9, 10, 12).

\section{Lagom}

Lennon et al. $^{6}$ present a military health system COS for medical education, health care delivery, and public health. This article highlights the relative ease of creating meaningful COSs in the cohesive military communication structure. The authors also propose a compelling definition for the correct size of a COS: lagom - "while there is no direct English translation, lagom essentially means 'just the right amount'.... The local COS is an organic entity that will expand and contract in scope until it reaches the right size for the patient community it serves, as measured by the outcomes it chooses to achieve" 6 (grand challenges 2, 8, 9, 10, and 13). In contrast, the OCHIN Community Information Network ${ }^{7}$ identifies "problem sheds through surveillance of network-wide data" by facilitating locally relevant data sharing among public health partners, community health stakeholders, informatics, and policy. This place-based data component of a COS, although on its face less relationship-based, also enables understanding and outcomes measurement of any identified community health problem (grand challenges 1, 10, 11, and 13).

COSs are indispensable to the mitigation of health disparities because of social determinants of health. A collaboration between the Jefferson Department of Family and Community Medicine 
Figure 1. Example of a community of solution to address a specific problem shed. Reprinted with permission of the publisher from Health Is a Community Affair, by the National Commission on Community Health Services, p. 3 , Cambridge, MA: Harvard University Press, $\odot 1966$ by the President and Fellows of Harvard College.

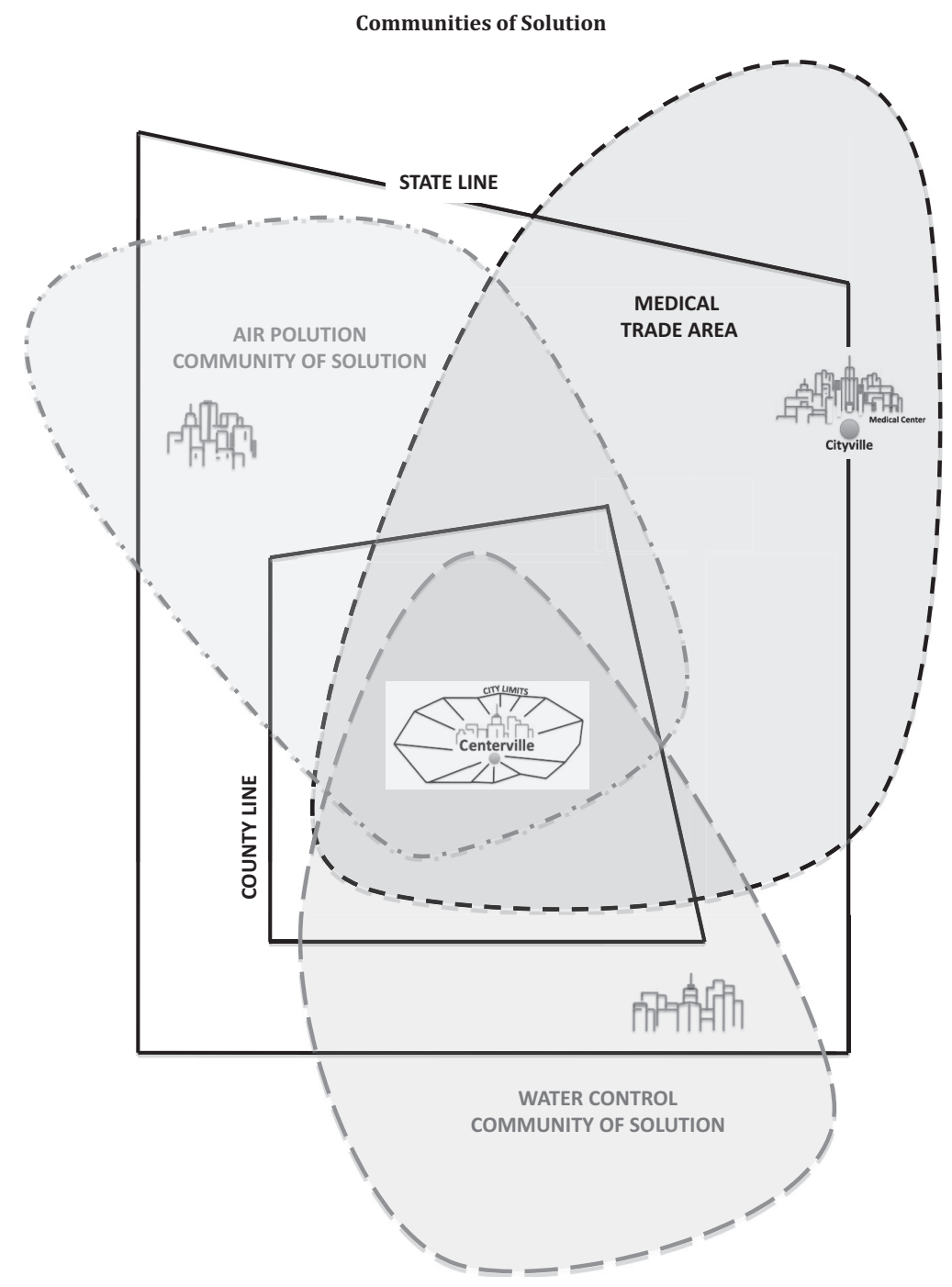

and Pathways to Housing-PA creates a jurisdiction crossing lagom COS for a homeless and mentally ill population (grand challenges 2, 3, 9, and 10). Weinstein et $\mathrm{al}^{8}$ highlight the current reality that many of these COS roles are "not about to be reimbursed under current insurance mechanisms." This program provides evidence for the ongoing relevance and breadth of the Folsom Report and the COS framework in addressing the needs of individuals and communities.

\section{Rural and Urban Lagom}

In "HeartBeat Connections" (grand challenges 4, $7,11,12$, and 13), Benson et $\mathrm{al}^{9}$ describe a rural program using participatory methods. Recogniz- ing "common barriers to clinical CVD prevention (eg, lack of time and lack of patient followup)", 9 the project utilizes a multidisciplinary team for counseling and medication management through telephone outreach. Participants also are linked "to other resources within the community (eg, weight management classes, fitness facilities, and farmers' markets), thereby integrating medicine and public health."9

Sanders et $\mathrm{al}^{10}$ focus on social determinants of health through their inner-city chronic disease management program with "nurse-led teams using protocol-driven clinical decision-making situated in 2 neighborhood food pantries" to focus on hypertension, hyperlipidemia, and diabetes (grand 
challenges 4, 7, 8, 12, and 13). Their Milwaukee model incorporates a network formed by volunteers, community health workers, local parishes, and strong faith-based connections. In a wider community focus, Baird Kanaan ${ }^{11}$ describes the Healthy Mendocino COS as a "broad-based coalition" consisting of 20 community stakeholders with pooled funding to launch a web-based tool that will enhance the quality and utility of data for improving local health (grand challenges 7, 8, 11,12 , and 13).

These 3 examples focus on specific community problem sheds: urban, rural, and community wide, emphasizing the utility of Figure 1.

\section{COS: Back to the Future}

Can the U.S. public school system serve as a roadmap for health system reforms? (grand challenges $1-13)$ DeVoe and Gold ${ }^{12}$ pose this question in a future-forward essay exploring how a neighborhood-based COS might use community health centers, public health outreach, information technology, and citizen-driven district health boards to deliver coordinated, efficient care.

\section{Influences of the Pharmaceutical Industry}

Two final articles discuss the influence of the pharmaceutical industry and the impact of physician disclosure under health care reform-the "Sunshine laws." In "Physician Payment Disclosure Under Healthcare Reform: Will the Sun Shine?" (grand challenges 8, 10,11, and 13), Mackey and Liang $^{13}$ illustrate the intent of regulation efforts to control pharmaceutical costs and mitigate conflicts of interests for providers. Evans et $\mathrm{al}^{14}$ (grand challenges 10, 12, and 13) have an answer to the pharma dilemma: engage in a pharma-free practice redesign. Their clinic transformation includes consensus agreement by clinical and front office staff, detailed cost data on drug samples, and monitoring of pharma visits, all done as part of a quality improvement initiative.

\section{The Payer Conundrum}

It is interesting that none of the articles presented include a defined role for insurance companies within the COS; ideally payment would be a powerful incentive to create effective problem-solving structures for problem sheds. However, coverage guidelines from insurance stakeholders may con- fuse patients about whether the clinician or the insurance provider is actually making care decisions, which creates an inherent conflict within a COS. We believe that payers will become involved in development and support of COSs because their patients derive benefit from living and working in a community that values healthy living. Could an effective accountable care organization actually be a COS with payers included? We hope that visionary payers will accept the grand challenges of the Folsom legacy and begin immediately supporting the development of true COSs in their neighborhoods, catchment areas, and states.

\section{Folsom Forward}

These articles illustrate exciting opportunities and COS models and highlight persistent health disparities that plague our nation. COSs may be crucial steps toward addressing social determinants of health. Positive change is anchored to sustainable community approaches that link public health and primary care in explicit partnerships to address the needs of the individual and community. Together, when we build a COS, an environment and a neighborhood that supports healthy living, we contribute to the health of the whole population.

The Folsom Group: Sarah Lesko, MPH, Center for Researching Health Outcomes, Mercer Island, WA; Kim S, Griswold, MD, MPH, University of Buffalo, SUNY School of Medicine and Biomedical Sciences, Buffalo, NY; Sean P. David, MD, SM, DPhil, Stanford University School of Medicine, Palo Alto, CA; Andrew W. Bazemore, MD, MPH, The Robert Graham Center for Policy Studies in Family Medicine and Primary Care, Washington, DC; Marguerite Duane, MD, MHA, Spanish Catholic Center of Catholic Charities, Washington, DC; Thomas Morgan, MD, Vanderbilt School of Medicine, Nashville, TN; John M. Westfall, MD, MPH, University of Colorado School of Medicine, Aurora, CO; C. Everett Koop, MD, SciD, The C. Everett Koop Institute at Dartmouth, Hanover, NH; Betsy Garrett, MD, University of Missouri School of Medicine, Columbia, MO; James C. Puffer, MD, The American Board of Family Medicine, Lexington, KY; and Larry A. Green, MD, University of Colorado School of Medicine, Aurora, CO, and the American Board of Family Medicine, Lexington, KY. 


\section{References}

1. NCCHS. Health is a Community Affair-Report of the National Commission on Community Health Services (NCCHS). Cambridge, MA: Harvard University Press; 1967.

2. The Folsom Group. Communities of solution: the Folsom Report revisited. Ann Fam Med 2012;10:250-60.

3. Ferrer RL, Gonzalez Schlenker C, Lozano Romero R, et al. Advanced primary care in San Antonio: linking practice and community strategies to improve health. J Am Board Fam Med 2013;26: 288-98.

4. Garney WR, Drake K, Wendel ML, McLeroy K, Clark HR, Ryder B. Increasing access to care for Brazos Valley, Texas: a rural community of solution. J Am Board Fam Med 2013;26:246-53.

5. Norman N, Bennett C, Cowart S, et al. Boot camp translation: a method for building a community of solution. J Am Board Fam Med 2013;26:254-63.

6. Lennon RP, Saguil A, Seehusen DA, Reamy BV, Stephens MB. The military health system: a community of solutions for medical education, health care delivery, and public health. J Am Board Fam Med 2013;26:264-70.

7. DeVoe JE, Sears A. The OCIN Community Information Network: bringing together community health centers, information technology, and data to support a patient-centered medical village. J Am Board Fam Med 2013;26:271-8.

8. Weinstein LC, LaNoue MD, Plumb JD, King H, Stein B, Tsemberis S. A primary care-public health partnership addressing homelessness, serious mental illness, and health disparities. J Am Board Fam Med 2013;26:279-87.

9. Benson GA, Sidebottom A, VanWormer JJ, Boucher JL, Stephens C, Krikava J. HeartBeat Connections: a rural community of solution for cardiovascular health. J Am Board Fam Med 2013;26:299-310.

10. Sanders J, Solberg B, Gauger M. Breaking barriers to care: a community of solution for chronic disease management. J Am Board Fam Med 2013;26: 311-5.

11. Baird Kanaan S. Early lessons and challenges from the Healthy Mendocino community of solution. J Am Board Fam Med 2013;26:316-22.

12. DeVoe JE, Gold R. Community of solution for the U.S. health care system: lessons from the U.S. educational system. J Am Board Fam Med 2013;26: 323-6.

13. Mackey TK, Liang BA. Physician payment disclosure under health care reform: will the sun shine? J Am Board Fam Med 2013;26:327-31.

14. Evans D, Hartung DM, Beasley D, Fagnan LJ. Breaking up is hard to do: lessons learned from a pharma-free practice transformation. J Am Board Fam Med 2013;26:332-8. 